\title{
Intervenção ambiental na cobertura e ventilação artificial sobre índices de conforto para aves de corte
}

\author{
Roberta Passini' ${ }^{1}$ Maria A. G. de Araújoํ, Vinícius M. Yasuda ${ }^{1}$ \& Eduardo A. Almeida ${ }^{1}$
}

\section{RESUMO}

Este trabalho objetivou avaliar manejos de cobertura e ventilação artificial sobre índices de conforto de frangos de corte. Aplicou-se, para avaliação dos índices térmicos, delineamento inteiramente casualizado, em parcela subdividida, com arranjo fatorial de tratamentos $2 \times 2$, sendo: dois manejos de cobertura (com e sem pintura reflexiva) e dois manejos internos (com e sem ventilação artificial) totalizando 4 tratamentos, avaliados durante 40 dias, tidos como repetição. Os estudos foram conduzidos no IFG - Campus Urutaí, de dezembro/2009 a janeiro/2010. Como variáveis ambientais foram coletadas as temperaturas de bulbo seco, bulbo úmido, globo negro, umidade relativa e velocidade do vento, sendo posteriormente calculados os índices térmicos: ITU, ITGU, ITE, TMR e CTR. Os dados foram analisados pelo programa computacional SISVAR por meio da análise de variância e teste de comparação de médias. Utilizou-se o Teste de Scott Knott considerando-se $5 \%$ de significância. A combinação de pintura branca na cobertura e ventilação artificial mostrou-se eficiente na melhoria do conforto térmico do ambiente estudado. A utilização de pintura ou ventilação artificial de forma isolada não foi eficiente.

Palavras-chave: ambiência, avicultura, construções rurais

\section{Environmental intervention in roof covering and artificial ventilation on the comfort indices for broilers}

\begin{abstract}
This study aimed to evaluate roof covering strategies and artificial ventilation on comfort indices of broilers. For the assessment of thermal indices, randomized design in split plots was used in a $2 \times 2$ factorial arrangement of treatments. Two management treatments of roof covering (with and without reflective paint) and two internal management (with and without artificial ventilation), totalizing 4 treatments were evaluated for 40 days, taking the days as replications. The studies were conducted in IFG - Urutaí Campus from December/2009 to January/2010. As environmental variables the dry bulb temperature, wet bulb, black globe, relative humidity and wind speed were considered and then the thermal indices THI, BGHI, ETI, RMT and RTR were calculated. Data were analysed by the SISVAR program, through the variance analysis and means were compared by Scott Knott test at 0.05 probability. The combination of white paint covering and artificial ventilation proved to be effective in improving the studied environmental thermal comfort. The use of paint or artificial ventilation in an isolated way was not efficient.
\end{abstract}

Key words: aviculture, environment, farm constructions 


\section{INTRODUÇÃO}

A avicultura industrial brasileira se encontra num patamar produtivo em que cada empresa deve tomar decisões relativas à adoção de concepções arquitetônicas e manejos inovadores, associados aos sistemas de condicionamento natural ou artificial dos galpões (Tinôco, 2001). A cobertura, inclinação do telhado, forro, pintura, beiral, pé direito, dimensão do galpão, cuidados com o entorno e sistemas mecânicos, são meios da edificação rural que, ao serem estudados e aplicados de forma adequada, podem ser exigidos em determinadas épocas do ano para solucionar os problemas do bioclima em caráter permanente (Franca et al., 2007).

Para Nããs et al. (2001), climatizar é adaptar o ambiente interno da construção às condições exteriores; atingir o conforto térmico no interior da instalação face às condições climáticas inadequadas, torna-se um desafio visto que situações de calor ou frio intensos afetam negativamente a produção.

Segundo Oliveira et al. (2000), o fator mais importante na manutenção do conforto térmico é a quantidade de radiação que chega até as aves, a qual é determinada pelo tipo de material de cobertura ou pela presença de um isolante térmico que, de maneira geral, é um dos meios mais econômicos de melhorar as condições ambientais em edificações. A cobertura é responsável por aproximadamente $80 \%$ da absorção de calor por radiação e a cor enegrecida dos telhados é um agravante para a retenção de calor (Tinôco, 2001).

Conforme Sarmento et al. (2005) a cor branca da superfície externa da cobertura é um artifício simples e eficiente na redução da temperatura da superfície interna da cobertura reduzindo em até $9{ }^{\circ} \mathrm{C}$ a temperatura nos horários mais quentes do dia. Conceição et al. (2008) verificaram que a aplicação de pintura reflexiva na face externa de coberturas de cimento amianto favoreceu a situação de conforto térmico em modelos reduzidos de galpões avícolas, apresentando valores de TGN (Temperatura de globo negro), ITU e CTR significativamente menores que os obtidos utilizando-se telhas cerâmicas e telhas compostas de fibra vegetal, demonstrando que o efeito da refletividade da tinta branca foi superior ao efeito da transmissividade das telhas cerâmicas.

Por outro lado, a ventilação é um meio eficiente de reduzir a temperatura dentro das instalações avícolas e de renovar a oxigenação do ambiente, por aumentar as trocas térmicas de convecção (Sevegnani et al., 2001). Para Ronchi (2004) a falta de ventilação pode ocasionar aumento da umidade relativa do ar, aumento na concentração de gases tóxicos como amônia e dióxido de carbono, aumento na concentração de poeira e baixa concentração de oxigênio disponível.

Isto posto, objetivou-se avaliar o uso de diferentes manejos de cobertura associados ou não à ventilação artificial, sobre variáveis ambientais e índices de conforto térmico para aves de corte.

\section{Material e Métodos}

O experimento foi conduzido no Instituto Federal Goiano (IFG) - Campus de Urutaí, localizado na rodovia Geraldo Silva Nascimento, km 2,5, zona rural de Urutaí, no período de 15 de dezembro de 2009 a 25 de janeiro de 2010. A região localizase a uma altitude de $744 \mathrm{~m}$, latitude $17^{\circ} 27^{\prime} 49^{\prime \prime} \mathrm{S}$ e longitude $48^{\circ} 12^{\prime} 06^{\prime \prime}$ O. O clima da região, segundo classificação de Koeppen, é Cwa caracterizado como clima temperado quente, com chuvas de verão e temperatura média do ar no mês mais quente superior a $22{ }^{\circ} \mathrm{C}$.

Foi utilizado um galpão para criação de frangos de corte, com orientação $32^{\circ} \mathrm{NO}$, medindo $21,25 \mathrm{~m}$ de comprimento $\mathrm{x}$ $8,00 \mathrm{~m}$ de largura, muretas com $0,46 \mathrm{~m}$ de altura, pé direito de $3,0 \mathrm{~m}$, coberto com telhas de cimento amianto, piso concretado, laterais protegidas com telas de arame galvanizado, cortinas manuais, parede de alvenaria, semi-aberta, pintada de branco e revestida de tinta e cal.

O galpão foi alojado com aves de corte na densidade de 10,6 aves $\mathrm{m}^{-2}$, distribuídas aleatoriamente em 16 boxes, com dimensões de 1,30 x 2,18 m. Os tratamentos foram aplicados em um mesmo galpão sendo os microclimas mantidos pelo isolamento com lona plástica dupla, de forma a promover isolamento por bolsões de ar entre elas, colocadas de forma que possibilitou a divisão do galpão em quatro partes, as quais foram preparadas para a comparação experimental. Foi utilizado um delineamento inteiramente casualizado, em parcela subdividida, com arranjo fatorial de tratamentos $2 \times 2$, correspondendo a dois manejos externos (cobertura com e sem pintura reflexiva) e dois manejos internos (com e sem ventilação artificial) totalizando 4 tratamentos.

A pintura reflexiva foi realizada com tinta látex branca, aplicada na parte externa do telhado, em duas demãos, realizada após a lavagem das telhas de cimento amianto. Para a ventilação artificial do galpão utilizaram-se ventiladores axiais de três pás, da marca WEG modelo W21, com potência de $0,5 \mathrm{cv}, 1.100 \mathrm{rpm}$ e vazão de $330 \mathrm{~m}^{3} \mathrm{~min}^{-1}$, acionados quando a temperatura interna do galpão atingia $25^{\circ} \mathrm{C}$, sendo desligados quando a temperatura declinava para $21{ }^{\circ} \mathrm{C}$. Em função da abertura lateral do galpão e seu tamanho reduzido, a renovação do ar nas parcelas ocorria em aproximadamente 3 a 5 minutos. Em cada tratamento foram coletadas as variáveis ambientais: temperatura de globo negro (Tgn), temperatura de bulbo seco (Tbs), temperatura de bulbo úmido (Tbu), umidade relativa do ar (UR) e velocidade do vento (v) mensuradas diariamente, nos horários das 7, 9, 12, 14, 16 e 18 h, durante 40 dias, tidos como repetição.

Para a obtenção da temperatura de globo negro foram utilizados termômetros de globo, confeccionados com esferas de plástico (bóias) pintadas com tinta preta fosca possuindo, na região central interna, termômetro decimal de mercúrio, modelo ASTM, com escala de $-10 \mathrm{a}+50{ }^{\circ} \mathrm{C}$, precisão $0,1{ }^{\circ} \mathrm{C}$, Instrutemp ${ }^{\circledR}$. A umidade relativa e a temperatura de bulbo seco foram coletadas por meio de um termo-higrômetro digital, com escala de 0 a $100 \%$ e precisão de $1 \%$ para a umidade relativa e escala de -15 a $55{ }^{\circ} \mathrm{C}$ e precisão de 0,1 ${ }^{\circ} \mathrm{C}$ para a temperatura do ar, da marca Equitherm ${ }^{\circledR}$. Foram utilizados um psicrômetro -10 a $50{ }^{\circ} \mathrm{C}$ e divisão de $1{ }^{\circ} \mathrm{C}$, Instrutemp ${ }^{\circledR}$, para a coleta da temperatura de bulbo úmido, sendo usada posteriormente para o cálculo da temperatura do ponto de orvalho e confecção dos índices térmicos. O globo negro e o termo-higrômetro foram instalados a nível do centro de massa das aves, a uma altura de $30 \mathrm{~cm}$ da cama e a medição 
da velocidade do vento foi realizada a $35 \mathrm{~cm}$ acima do nível da cama, com auxílio de um anemômetro digital de hélice, com limiar de 0,1 e precisão de $\pm 5 \%$, modelo ITWM 1850 ,

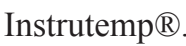

A temperatura radiante média (TRM) é a temperatura de uma circunvizinhança considerada uniformemente negra, de modo a eliminar o efeito de reflexão com o qual um corpo troca energia (Bond \& Kelly, 1955). A TRM é expressa pela Eq. 1:

$$
\mathrm{TMR}=100\left[2,51 \times(\mathrm{v}) 0,5 \times(\mathrm{Tgn}-\mathrm{Tbs})+\left(\frac{\mathrm{Tgn}}{100}\right)^{4}\right]^{1 / 4}
$$

em que:

v - velocidade do vento, $\mathrm{m} \mathrm{s}^{-1}$

Tgn - temperatura de globo negro, $\mathrm{K}$

Tbs - temperatura de bulbo seco, $\mathrm{K}$

Posteriormente ao cálculo da TMR foi calculada a carga térmica de radiação (CTR, $\mathrm{W} \mathrm{m}^{-2}$ ) conforme a Eq. 2:

$$
\mathrm{CTR}=\sigma \times(\mathrm{TRM})^{4}
$$

em que:

$\sigma \quad$ - constante de Stefan-Boltzmann $\left(5,67.10^{-8} \mathrm{~W} \mathrm{~m}^{-2} \mathrm{~K}^{-4}\right)$

TRM - temperatura radiante média, $\mathrm{K}$

O índice de temperatura e da umidade (ITU) relaciona a temperatura do ar com a umidade relativa, podendo ser expresso pela Eq. 3 (Baêta \& Souza, 2010).

$$
\mathrm{ITU}=\mathrm{Tbs}+0,36 \times \mathrm{Tpo}+41,5
$$

em que:

Tbs - temperatura de bulbo seco, ${ }^{\circ} \mathrm{C}$

Tpo - temperatura de ponto de orvalho, ${ }^{\circ} \mathrm{C}$

O índice de temperatura de globo negro e umidade (ITGU) foi calculado de acordo com a Eq. 4, proposta por Buffington et al. (1981):

$$
\mathrm{ITGU}=\mathrm{Tgn}+0,36 \times \mathrm{Tpo}+41,5
$$

em que:

Tgn - temperatura de globo negro, ${ }^{\circ} \mathrm{C}$

Tpo - temperatura de ponto de orvalho, ${ }^{\circ} \mathrm{C}$

O índice de temperatura equivalente (ITE) foi calculado pela Eq. 5, proposta por Baêta \& Souza (2010):

$$
\begin{aligned}
\mathrm{ITE} & =27,88-0,456 \times \mathrm{Tbs}+0,0100754 \times \mathrm{Tbs}^{2}- \\
& -0,4905 \times \mathrm{UR}+0,00088 \mathrm{UR}^{2}+ \\
& +1,1507 \times \mathrm{v}-0,126447 \times \mathrm{v}^{2}+ \\
& +0,019876 \times \mathrm{Tbs} \times \mathrm{UR}-0,046313 \times \mathrm{Tbs} \times \mathrm{v}
\end{aligned}
$$

em que:

$$
\begin{aligned}
& \text { Tbs - temperatura de bulbo seco, }{ }^{\circ} \mathrm{C} \\
& \text { V } \\
& \text { UR }
\end{aligned}
$$

Os dados foram analisados pelo programa computacional SisVar $5.1 \circledR$, por meio da análise de variância. Como premissas foram verificadas a homogeneidade das variâncias e a normalidade dos resíduos. Quando necessário, os dados foram transformados pela raiz quadrada. O teste de Scott Knott foi utilizado para comparação das médias das variáveis ambientais considerando-se 5\% de significância.

\section{Resultados E Discussão}

Observou-se interação entre os fatores estudados para Tgn e Tbs $(\mathrm{P}<0,01)$. A pintura branca promoveu, combinada com a ventilação artificial, melhores resultados referentes à temperatura de globo negro e temperatura de bulbo seco apresentando valores inferiores àqueles observados nos demais tratamentos reduzindo, em média, $0,9^{\circ} \mathrm{C}$. Constatou-se, mesmo com a redução dos valores de temperatura no interior da instalação promovida pelo uso da pintura, que os valores ultrapassam aqueles tidos como faixa de conforto térmico para aves de corte, entre 18 e $26{ }^{\circ} \mathrm{C}$, conforme Campos (1995) e Baeta \& Souza (2010).

Furtado et al. (2010) não observaram em seus estudos em região semiárida, diferenças significativas na temperatura ambiente e umidade relativa quando compararam galpões com cobertura de telha barro ou telha de fibrocimento; contudo, relataram que a temperatura do ar esteve acima do limite da zona de termoneutralidade recomendada para frangos de corte nos dois ambientes; entretanto, Vitorasso \& Pereira (2009) observaram, avaliando galpões avícolas com telha de cerâmica e telha de cimento amianto, no estado de São Paulo, valores superiores de temperatura interna de telha para cimento amianto em relação à cobertura cerâmica.

Houve efeito principal da pintura reflexiva sobre a UR $(\mathrm{P}<0,05)$. A utilização da pintura reflexiva sobre o telhado promoveu uma diferença significativa na umidade relativa (66,88\%) quando comparado com o dos tratamentos sem pintura reflexiva $(65,70 \%)$. Os valores obtidos de umidade relativa no presente estudo se encontram dentro da faixa de conforto que, de acordo com Tinôco (2004) se situam entre 50 e $70 \%$.

Houve diferença significativa para os valores de temperatura de globo negro entre os tratamentos com a presença ventilação artificial $\left(28,17{ }^{\circ} \mathrm{C}\right)$ e com a ausência de ventilação artificial $\left(28,61{ }^{\circ} \mathrm{C}\right)$ sendo que a utilização da ventilação artificial mostrou-se eficiente na redução da temperatura ambiente $(\mathrm{P}<0,01)$. Vigoderis et al. (2010) observaram, estudando a influência da ventilação mínima no conforto térmico e qualidade do ar em galpões avícolas, que o uso de ventilação mínima resulta ainda em menores valores de concentração de gases no interior dos galpões favorecendo a manutenção da qualidade do ar.

Observou-se, para o manejo de pintura reflexiva sobre o telhado, diferença significativa para Tgn, Tbs e UR (efeito principal) tendo-se verificado, ainda, menores valores de 
Tgn e Tbs e maior UR no ambiente com pintura, mas não se verificando diferenças significativas para o uso ou não de ventilação artificial.

$\mathrm{Na}$ Tabela 1 se encontram as médias de temperatura de globo negro (Tgn), temperatura de bulbo seco (Tbs), umidade relativa (UR) e velocidade do vento (v) com os respectivos coeficientes de variação e probabilidades estatísticas.

Tabela 1. Médias das variáveis ambientais, temperatura de globo negro (TGN), temperatura de bulbo seco (TBS), umidade relativa (UR) e velocidade (V) do vento para os diferentes fatores e suas interações, com os respectivos coeficientes de variação e probabilidades estatísticas

\begin{tabular}{|c|c|c|c|c|c|}
\hline \multicolumn{2}{|c|}{ Causas de variação } & TGN & TBS & UR & $V^{* * *}$ \\
\hline \multicolumn{6}{|c|}{ Efeitos principais* } \\
\hline \multicolumn{2}{|l|}{ Com pintura } & $28,18 \mathrm{a}$ & 27,76 a & $88 \mathrm{a}$ & 0,31 \\
\hline \multicolumn{2}{|l|}{ Sem pintura } & $28,60 \mathrm{~b}$ & $28,03 \mathrm{~b}$ & $65,70 \mathrm{~b}$ & 0,34 \\
\hline \multicolumn{2}{|c|}{ Com ventilação } & $28,17 \mathrm{a}$ & 27,79 & 66,16 & $0,65 a$ \\
\hline \multicolumn{2}{|c|}{ Sem ventilação } & $28,61 \mathrm{~b}$ & 28,00 & 66,41 & $0,00 \mathrm{~b}$ \\
\hline \multicolumn{6}{|c|}{ Interações** } \\
\hline \multirow{2}{*}{ Pintura } & Com ventilação & $27,76 \mathrm{~A}$ & $27,49 \mathrm{~A}$ & 66,95 & 0,62 \\
\hline & & 28,6 & 28,0 & 66,80 & 0,00 \\
\hline \multirow{2}{*}{ Sem Pintura } & Com ventilação & $28,60 \mathrm{~B}$ & $28,10 \mathrm{~B}$ & 65,37 & 0,68 \\
\hline & Sem ventilação & $28,62 \mathrm{~B}$ & $27,96 \mathrm{~B}$ & 66,02 & 0,00 \\
\hline \multicolumn{6}{|c|}{ Probabilidades estatísticas } \\
\hline \multicolumn{2}{|l|}{ Pintura } & 0,0015 & 0,0258 & 0,0101 & 0,3438 \\
\hline \multicolumn{2}{|l|}{ Ventilação } & 0,0011 & 0,0848 & 0,5881 & 0,0001 \\
\hline \multicolumn{2}{|c|}{ Pintura x Ventilação } & 0,0025 & 0,0046 & 0,3843 & 0,3438 \\
\hline \multicolumn{2}{|l|}{ Média geral } & 28,39 & 27,90 & 66,29 & 0,32 \\
\hline \multicolumn{2}{|l|}{ C.V.(\%) } & 7,37 & 6,76 & 10,83 & 18,01 \\
\hline
\end{tabular}

As médias referentes aos valores de índice de temperatura e umidade (ITU), índice de temperatura de globo e umidade (ITGU), índice de temperatura equivalente (ITE), temperatura média radiante (TMR) e carga térmica radiante (CTR) são apresentadas na Tabela 2, com os respectivos coeficientes de variação e probabilidades estatísticas.

Foram observadas interações entre os tratamentos $(\mathrm{P}<0,01)$ para todos os índices estudados. A utilização da pintura branca sobre a cobertura combinada com a ventilação proporcionou redução nos valores de ITU $(76,8), \operatorname{ITGU}(77,0), \operatorname{TMR}(301,0)$ e CTR $(466,6)$ quando comparada com a ausência da pintura reflexiva, com ou sem ventilação artificial, que apresentaram valores médios de ITU, ITGU, TMR e CTR superiores, 77, 78,302 , e 473, respectivamente. Resultados diferentes foram encontrados por Sarmento et al. (2005) na Paraíba que, ao estudar o comportamento térmico de galpões avícolas, com e sem a presença de pintura reflexiva sobre a cobertura, aliada à ventilação artificial no interior da instalação, concluíram que a pintura externa não foi eficiente na diminuição dos índices térmicos.

Furtado et al. (2006) verificaram, estudando o uso de ventilação artificial, ventilação artificial e aspersão sobre a cobertura e ventilação artificial e nebulização, que houve redução na CTR, entre o sistema ventilação artificial e nebulização $\left(508,7 \mathrm{~W} \mathrm{~m}^{-2}\right)$ e os demais sistemas apenas no horário das $12 \mathrm{~h}$ sendo que o sistema apenas com ventilação
Tabela 2. Média dos índices de conforto térmico, índice de temperatura e da umidade (ITU), índice de temperatura de globo negro e umidade (ITGU), índice de temperatura equivalente (ITE), temperatura média radiante e carga térmica de radiação para os diferentes fatores e suas interações, com os respectivos coeficientes de variação e probabilidades estatísticas

\begin{tabular}{|c|c|c|c|c|c|c|}
\hline \multicolumn{2}{|c|}{ Causas de variação } & ITU & ITGU & ITE & TMR & CTR \\
\hline \multicolumn{7}{|c|}{ Efeitos principais* } \\
\hline \multicolumn{2}{|c|}{ Com pintura branca } & $77,0 \mathrm{a}$ & $77,5 \mathrm{a}$ & 30,5 & $301,4 \mathrm{a}$ & $468,7 \mathrm{a}$ \\
\hline \multicolumn{2}{|c|}{ Sem pintura branca } & $77,3 \mathrm{~b}$ & $78,0 \mathrm{~b}$ & 30,6 & $302,2 b$ & $473,9 \mathrm{~b}$ \\
\hline \multicolumn{2}{|c|}{ Com ventilação } & 77,1 & $77,5 \mathrm{a}$ & $30,2 a$ & 301,9 & 471,8 \\
\hline \multicolumn{2}{|c|}{ Sem ventilação } & 77,2 & $78,0 \mathrm{~b}$ & $30,9 \mathrm{~b}$ & 301,7 & 470,9 \\
\hline \multicolumn{7}{|c|}{ Interações** } \\
\hline \multirow{2}{*}{ Pintura } & Com ventilação & $76,8 \mathrm{~A}$ & $77,0 \mathrm{~A}$ & $30,1 \mathrm{~A}$ & $301,0 \mathrm{~A}$ & $466,6 \mathrm{~A}$ \\
\hline & Sem ventilação & $77,2 \mathrm{~B}$ & $78,0 \mathrm{~B}$ & $31,1 \mathrm{~B}$ & $301,7 \mathrm{a}$ & $470,9 \mathrm{~B}$ \\
\hline \multirow{2}{*}{ Sem Pintura } & Com ventilação & $77,4 \mathrm{~B}$ & $78,0 \mathrm{~B}$ & $30,4 \mathrm{~A}$ & $302,7 \mathrm{~B}$ & $477,1 \mathrm{C}$ \\
\hline & Sem ventilação & $77,2 \mathrm{~B}$ & $78,0 \mathrm{~B}$ & $30,8 \mathrm{~B}$ & $301,7 \mathrm{a}$ & $470,8 \mathrm{~B}$ \\
\hline \multicolumn{7}{|c|}{ Probabilidades estatísticas } \\
\hline \multicolumn{2}{|l|}{ Pintura } & 0,0259 & 0,0044 & 0,7030 & 0,0001 & 0,0001 \\
\hline \multicolumn{2}{|l|}{ Ventilação } & 0,1625 & 0,0043 & 0,0001 & 0,4489 & 0,3577 \\
\hline \multicolumn{2}{|c|}{ Pintura x Ventilação } & 0,0097 & 0,0021 & 0,0038 & 0,0001 & 0,0001 \\
\hline \multicolumn{2}{|l|}{ Média } & 77,20 & 77,70 & 30,60 & 301,80 & 471,40 \\
\hline \multicolumn{2}{|l|}{ C.V. $(\%)$} & 2,52 & 2,86 & 5,38 & 0,85 & 3,49 \\
\hline
\end{tabular}

* Letras minúsculas diferentes dentro das colunas, diferem estatisticamente pelo Teste de Scott Knott, dentro dos efeitos principais

** Letras maiúsculas diferentes dentro das colunas, diferem estatisticamente pelo Teste de Scott Knott, dentro das interações

apresentou o valor de 525,3 $\mathrm{W} \mathrm{m}^{-2}$ superior, portanto, aos valores de CTR encontrados neste estudo, podendo ser um indicativo do efeito benéfico da pintura reflexiva sobre a cobertura.

Sampaio et al. (2011) relataram, estudando diferentes tipos de cobertura, que a CTR variou de 406,7 a 479,2 $\mathrm{W} \mathrm{m}^{-2}$, de 405,0 a 480,5 $\mathrm{W} \mathrm{m}^{-2}$ e de 406,2 a 518,3 $\mathrm{W} \mathrm{m}^{-2}$ para telhas cerâmicas, de fibrocimento pintadas de branco e metálicas, respectivamente, sinalizando que as telhas cerâmicas e de fibrocimento com pintura reflexiva tiveram desempenhos semelhantes sendo superiores às telhas metálicas para a redução da carga térmica de radiação.

O uso da ventilação artificial no interior da instalação foi capaz de proporcionar uma diminuição significativa nos valores de ITGU $(77,5)$ e ITE $(30,2)$ quando comparada com a ausência da ventilação artificial no interior da instalação, que apresentou valores superiores de ITGU $(78,0)$ e ITE $(30,9)(P<0,01)$.

Para o tratamento sem pintura reflexiva e com ventilação artificial no interior da instalação foram observados valores de ITE $(30,4)$ inferiores aos apresentados no tratamento com pintura reflexiva sem ventilação artificial, que indicou ITE $(31,1)$. Analisando a TMR e CTR verificou-se que o tratamento sem pintura branca sobre a cobertura e sem ventilação artificial no interior da instalação apresentou valores inferiores de TMR $(301,7)$ e CTR $(470,8)$, quando comparado ao tratamento sem a pintura branca sobre a cobertura e com ventilação artificial no interior da instalação TMR $(302,7)$ e CTR $(477,1)$. Tal fato pode ser justificado pela orientação do galpão a $32^{\circ} \mathrm{NO}$ não se encontrando, predominantemente no sentido leste-oeste, recebendo maior radiação solar no tratamento sem pintura e com ventilação aumentando a TMR e a CTR.

Os valores de ITGU obtidos em todos os tratamentos permaneceram, segundo Baeta \& Souza (2010), dentro da 
Tabela 3. Média dos Índices de Temperatura de Globo Negro e Umidade nos diferentes tratamentos para os horários, com as respectivas probabilidades estatísticas e coeficiente de variação - CV (\%)

\begin{tabular}{|c|c|c|c|c|c|c|c|}
\hline \multirow{2}{*}{ Horários } & \multicolumn{4}{|c|}{ Tratamentos } & \multirow{2}{*}{ Médias } & \multirow{2}{*}{$\begin{array}{l}\text { C.V. } \\
\text { (\%) }\end{array}$} & \multirow{2}{*}{ Prob. F } \\
\hline & $P+V$ & $P+S V$ & $\mathrm{SP}+\mathrm{V}$ & $S P+S V$ & & & \\
\hline 7:00 & 70,69 & 70,65 & 70,50 & 70,77 & 70,65 & & 0,9548 \\
\hline 9:00 & 74,56 & 74,24 & 74,26 & 74,81 & 74,47 & & 0,5925 \\
\hline 12:00 & $78,98 \mathrm{a}$ & $79,70 \mathrm{~b}$ & $80,04 \mathrm{~b}$ & $80,24 b$ & 79,74 & & 0,0470 \\
\hline $14: 00$ & $80,37 a$ & $81,12 b$ & $81,60 \mathrm{~b}$ & $81,25 b$ & 81,24 & 2,8 & 0,0122 \\
\hline $16: 00$ & $79,82 \mathrm{a}$ & $80,72 b$ & $81,07 \mathrm{~b}$ & $80,96 b$ & 80,64 & & 0,0391 \\
\hline 18:00 & $78,26 \mathrm{a}$ & $81,30 \mathrm{~b}$ & $80,26 \mathrm{c}$ & $78,91 \mathrm{a}$ & 79,68 & & 0,0001 \\
\hline
\end{tabular}

$\mathrm{P}+\mathrm{V}=$ pintura branca +ventilação, $\mathrm{P}+\mathrm{SV}=$ pintura branca, sem ventilação; SP $+\mathrm{V}=$ sem pintura branca + ventilação; SP $+\mathrm{SV}=\mathrm{sem}$ pintura branca, sem ventilação

* Médias seguidas de letras diferentes na linha diferem estatisticamente pelo teste de Scott Knott, a 0,05 de probabilidade

zona de alerta para aves de corte, caracterizada por valores de ITGU entre 74 e 78; sendo assim, em todos os tratamentos os valores médios de ITGU $(77,7)$ foram desfavoráveis para a criação de aves, mesmo com o uso combinado de pintura reflexiva e ventilação artificial.

De acordo com a Tabela 3 a hora mais crítica em relação ao ITGU foi às $14 \mathrm{~h}$, apresentando valor médio de 81,24 . Em seu estudo, Jácome et al. (2007) corroboram com esta observação; referidos autores verificaram maior valor de ITGU às $14 \mathrm{~h}$ horário este, portanto, de maior desconforto térmico para as aves. $\mathrm{O}$ tratamento pintura e ventilação foi estatisticamente mais eficiente $(\mathrm{P}<0,05)$ que os demais tratamentos na redução do ITGU, nos horários das 12, 14 e $16 \mathrm{~h}$, apresentando maior valor às $14 \mathrm{~h}(80,3)$. Resultado semelhante obtiveram Moraes et al. (1999) neste mesmo horário, em que o valor médio do ITGU igual a $86,3 \mathrm{em}$ telha com pintura reflexiva e o valor de 83,2 de ITGU em telhado de amianto sem pintura.

Foram constatados efeito principal da pintura reflexiva ( $\mathrm{P}$ $<0,01)$ e interação entre pintura e ventilação $(\mathrm{P}<0,01)$ para os índices TMR e CTR; não se observou, no entanto, efeito principal de ventilação para esses índices. $\mathrm{O}$ uso combinado dos manejos pintura e ventilação promoveu valores inferiores de CTR e TMR em relação aos demais tratamentos $(\mathrm{P}<0,01)$.

$\mathrm{O}$ valor máximo médio de ITGU atingido pelo tratamento composto de pintura e ventilação, foi de 80,37 enquanto os demais tratamentos atingiram valores superiores a 81 . O tratamento sem uso da pintura mas com ventilação artificial, apresentou valores de ITGU acima de 80 a partir das $12 \mathrm{~h}$, não reduzindo este valor até a última medição diária, $\mathrm{O}$ mais alto valor de ITGU foi observado às $18 \mathrm{~h}$, para o tratamento com pintura e sem ventilação.

A partir das $9 \mathrm{~h}$ todos os valores de ITGU se apresentaram acima daqueles tidos como de conforto térmico para aves, sendo que a partir das $12 \mathrm{~h}$ todos os valores de ITGU ultrapassaram 78, que são valores que comprometem o desenvolvimento das aves (Baeta \& Souza, 2010). Resultados semelhantes foram encontrados por Sarmento et al. (2005) ao verificar que para a última semana de criação das aves o ITGU entre 78 e 80,5 comprometeu diretamente o desenvolvimento das aves caracterizando uma situação de desconforto térmico.

De outra forma, Rocha et al. (2011) não observaram, estudando galpões cobertos com telhas de cerâmica ou de fibrocimento no estado da Paraíba, diferença entre os galpões para temperatura e umidade relativa do ar, índice de temperatura de globo negro e umidade, carga térmica de radiação e a velocidade do vento porém nos horários mais quentes do dia (10 às 16 h) os autores verificaram valores médios acima da zona de conforto causando situação de desconforto para as aves; contudo, não influenciaram negativamente o desempenho produtivo.

\section{Conclusões}

1. O uso combinado da pintura reflexiva sobre a cobertura e ventilação artificial no interior da instalação mostrou-se mais eficiente na manutenção dos índices de conforto térmico ITU e ITGU e na redução da CTR do ambiente do que o uso isolado dos mesmos.

2. A utilização da pintura branca sobre o telhado, aliada à ventilação artificial, não foi suficiente para manter índices térmicos ideais para criação de aves de corte.

\section{Literatura Citada}

Baêta, F. C.; Souza, C. F. Ambiência em edificações rurais: Conforto animal. 2.Ed. Viçosa: EDUFV, 2010, 269p.

Bond, T. E.; Kelly, C. F. The globe thermometer in agricultural research. Agricultural Engineering, v.36, p.251-260, 1955.

Buffington, D. E.; Colazzo-Arocho, A.; Canton, G. H.; Pitt, D. Black globe-humidity index (BGHI) as comfort equation for dairy cows. Transaction of the ASAE, v.24, p.711-714, 1981.

Campos, E. J. Programa de alimentação e nutrição para aves de acordo com o clima. Reprodutoras. In: Simposio Internacional de Ambiência e Instalação na Avicultura Industrial, 1995, Campinas. Anais... Campinas: FACTA, 1995. p.251-257.

Conceição, M. N.; Alves, S. P.; Telatin Júnior, A.; Silva, I. J. O.; Piedade, S. M. S.; Savastano Júnior, H.; Tonoli, G. Desempenho de telhas de escória de alto forno e fibras vegetais em protótipos de galpões. Revista Brasileira de Engenharia Agrícola e Ambiental, v.12, p.536-539, 2008.

Franca, M. L.; Camerini, N. L.; Mendes, L. B.; Silva, V. R. da; Furtado, D. A. Diagnóstico bioclimático para aves de corte no município de campina grande - PB. Revista Educação Agrícola Superior, v.22, p.53-56, 2007.

Furtado, D. A.; Dantas, R. T.; Nascimento, J. W. B. do; Santos, J. T.; Costa, F. G. P. Efeitos de diferentes sistemas de acondicionamento ambiente sobre o desempenho produtivo de frangos de corte. Revista Brasileira de Engenharia Agrícola e Ambiental, v.10, p.484-489, 2006. 
Furtado, D. A.; Rocha, H. P.; Nascimento, J. W. B. do; Silva, J. H. V. Índices de conforto térmico e concentração de gases em galpões avícolas no semiárido paraibano. Engenharia Agrícola, v.30, p.993-1002, 2010.

Jácome, I. M. T. D.; Furtado, D. A.; Leal, A. F.; Silva, J. H. V.; Moura, J. F. P. Avaliação de índices de conforto térmico de instalações para poedeiras no Nordeste do Brasil. Revista Brasileira de Engenharia Agrícola e Ambiental, v.11, p.527-531, 2007.

Moraes, S. R. P.; Tinôco, I. F. F.; Baêta, F. C.; Cecon, P. C. Conforto térmico em galpões avícolas, sob coberturas de cimento amianto e suas diferentes associações. Revista Brasileira de Engenharia Agrícola e Ambiental, v.3, p.89-92, 1999.

Nããs, I. A.; Sevegnani, K. B.; Marcheto, F. G.; Espelho, J. C. C.; Menegassi, V.; Silva, I. J. O. Avaliação térmica de telhas de composição de celulose e betumem, pintadas de branco, em modelos de aviários com escala reduzida. Engenharia Agrícola, v.21, p.121-126, 2001.

Oliveira, J. E.; Sakomura, N. K.; Figueiredo, A. N.; Lucas Júnior, J.; Santos, T. M. B. Efeito do Isolamento térmico de telhado sobre o desempenho de frangos alojados em diferentes densidades. Revista Brasileira de Zootecnia, v.29, p.1427-1434, 2000.

Rocha, H. P.; Furtado, D. A.; Nascimento, J. W. B. do; Silva, J. H. $\mathrm{V}$. Índices bioclimáticos e produtivos em diferentes galpões avícolas no semiárido paraibano. Revista Brasileira de Engenharia Agrícola e Ambiental, v.14, p.1330-1336, 2010.

Ronchi, C.Principais práticas de manejo para aves recémnascidas (2004). Disponível em: <http://centrodepesquisasavicolas. files.wordpress.com/2011/03/manejo-de-aves-recc3a9mnascidas.pdf $>$. Acesso em: 10 abr. 2011.
Sampaio, C. A. P; Cardoso, C. O.; Souza, G. P. Temperaturas superficiais de telhas e sua relação com ambiente térmico. Revista Engenharia Agrícola, v.31, p.230-236, 2011.

Sarmento, L. G. V.; Dantas, R. T.; Furtado, D. A.; Nascimento, J. W. B. do; Silva, J. H. V. Efeito da Pintura Externa do Telhado Sobre o Ambiente Climático e Desempenho de Frangos de Corte. Agropecuária Técnica, p.117-122, 2005

Sevegnani, K. B.; Moura, D. J.; Silva, I. J. O.; Macari, M.; Nääs, I. A. Perdas de calor sensível e latente em frangos de corte aos 49 dias, expostos à ventilação forçada. In: Reunião Anual da Sociedade Brasileira de Zootecnia. Anais..., 38, FEALQ. Piracicaba, p.16-17, 2001.

Tinôco, I. de F. F. Ambiência e instalações na produção de matrizes avícolas. In: Silva, I. J. O. Ambiência na produção de aves em clima tropical. v.2. Piracicaba: ESALQ, 2001. p.150-214.

Tinoco, I. de F. F. A granja de frangos de corte. In: Mendes, A. A.; Nääs, I. A.; Macari, M. Produção de frangos de corte. Campinas, cap. 4, p.55-84. SP, FACTA. 2004.

Vigoderis, R. B.; Cordeiro, M. B.; Tinôco, I. de F. F.; Menegali, I.; Souza Júnior, J. P. S.; Holanda, M. C. R. Avaliação do uso de ventilação mínima em galpões avícolas e de sua influência no desempenho de aves de corte no período de inverno. Revista Brasileira de Zootecnia, v.39, p.13811386, 2010.

Vitorasso, G.; Pereira, D. F. Análise comparativa do ambiente de aviários de postura com diferentes sistemas de acondicionamento. Revista Brasileira de Engenharia Agrícola e Ambiental, v.13, p.788-794, 2009. 